\title{
Factors associated with contracting malaria in Ward 29 of Shamva District, Zimbabwe, 2014
}

\author{
G Muchena, ${ }^{1} \mathrm{MB}$ ChB, MPH; N Gombe, ${ }^{1}$ BTech, MPH; L Takundwa, ${ }^{1} \mathrm{MB}$ ChB, MPH; M Tshimanga, ${ }^{1} \mathrm{MD}, \mathrm{MPH} ; \mathrm{D}$ Bangure, ${ }^{1} \mathrm{BSc}, \mathrm{MPH}$; \\ N Masuka, ${ }^{2} \mathrm{MB} \mathrm{ChB}, \mathrm{MPH}$; T Juru, ${ }^{1} \mathrm{BSc}, \mathrm{MPH}$ \\ ${ }^{1}$ Department of Community Medicine, College of Health Sciences, University of Zimbabwe, Harare, Zimbabwe \\ ${ }^{2}$ Provincial Medical Directorate, Matabeleland North Province, Ministry of Health and Child Care, Bulawayo, Zimbabwe
}

Corresponding author: T Juru (tsitsijuru@gmail.com)

\begin{abstract}
Background. Malaria cases at Wadzanayi Clinic in Shamva District, Zimbabwe, increased drastically, surpassing the epidemic threshold, in week four of December 2013. This rise was sustained, which necessitated an investigation of the outbreak.

Objectives. To identify risk factors and system weaknesses to improve epidemic preparedness and response.

Methods. An unmatched 1:1 case-control study was conducted in Ward 29 of Shamva District in Zimbabwe. Epidemic preparedness and response were assessed using the Zimbabwean epidemic preparedness and response guidelines.

Results. The sociodemographic characteristics of all participants were similar, except for gender. The risk factors for contracting malaria were performing early morning chores (odds ratio (OR) 2.75 ; $95 \%$ confidence interval (CI) 1.20 - 6.32), having a body of water near the home (OR 3.41; 95\% CI 1.62 - 7.20) and having long grass near the home (OR 2.61; 95\% CI 1.10 - 6.37). Protective factors were staying indoors at night (OR 0.13; 95\% CI 0.06 - 0.28) and staying in a sprayed home (OR 0.36; 95\% CI 0.21 - 0.92 ). All cases were diagnosed with a malaria rapid diagnostic test. All complicated cases were treated with quinine. Four out of 58 uncomplicated cases were treated with quinine. The rest were treated with co-artemether. There was no documentation of the outbreak response by the district health executive. Respraying (indoor residual spraying) was carried out, with a coverage of $78 \%$ of rooms sprayed. One nurse out of seven at Wadzanayi Clinic was trained in integrated disease surveillance and response, and malaria case management. District malaria thresholds were outdated. Malaria commodities such as drugs and sprays did not have reorder limits.

Conclusion. This study re-emphasises the importance of environmental- and personal-level factors as determinants of malaria. Poor outbreak preparedness and response may have propagated the malaria outbreak in this setting. Health education and the use of mosquito repellants should be emphasised. Larvicide may reduce the malaria burden. Epidemic preparedness and response need to be strengthened. Outbreak investigation remains important. This study emphasises the need for malaria interventions to be tailored to locally prevailing determinants to avert outbreaks.
\end{abstract}

S Afr Med J 2017;107(5):420-423. DOI:10.7196/SAMJ.2017.v107i5.12204

Zimbabwe has unstable malaria transmission with seasonal epidemics. All age groups are at risk of contracting the disease..$^{[1]}$

Malaria remains a major public health problem in Zimbabwe, where more than 5 million people are estimated to be at risk of contracting the disease annually. The burden of malaria in Zimbabwe has been declining owing to changing weather patterns, the use of dichloro-diphenyl-trichloroethane (DDT) for indoor residual spraying (IRS), the use of insecticide-treated nets and improved case management. ${ }^{[1]}$ However, some districts, such as Shamva, continue to use pyrethroids for IRS.

The National Malaria Control Programme is headed by a manager who is stationed at the Ministry of Health and Childcare head office in the capital city, Harare. The manager liaises at the provincial level via the provincial epidemiology and disease control officer. This officer reports to the provincial medical director and is responsible for co-ordinating malaria control activities at the provincial level. The overall accounting officer at the functional unit of the district is the district medical officer who is responsible for case management, surveillance and outbreak response.

Prior to 2015, complicated cases were treated using quinine. ${ }^{[2]}$ Zimbabwe now uses artemether-based combination therapy (ACT) as treatment for uncomplicated cases of malaria. The Cochrane group, however, recommends more trials on the effectiveness of ACT, as several trials have shown high rates of treatment failure. ${ }^{[3]}$ While microscopy is considered the gold standard for malaria diagnosis, clinicians are allowed to use malaria rapid diagnostic test (RDT) kits to confirm the diagnosis. Nurses and village health workers can initiate treatment with co-artemether upon diagnosis using these RDT kits.

Shamva District is located in Mashonaland Central Province of Zimbabwe, about $90 \mathrm{~km}$ north-east of the capital, Harare. It is characterised by moderate malaria transmission, which is seasonal. A major outbreak of malaria occurred in 2003 soon after the movement of a significant number of people into new farming areas. Shamva District utilises vector control, malaria case management, surveillance, health promotion and epidemic preparedness and response in efforts to reduce malaria transmission.

Shamva District Hospital and Wadzanayi Clinic are both located in Ward 29 of Shamva District. Patients in Wadzanayi Clinic's catchment area sometimes opt to be treated at Shamva District Hospital, leading to under-reporting of cases at Wadzanayi Clinic. Confirmed cases of malaria at Wadzanayi Clinic were consistently below epidemic thresholds during the month of November 2013, recording fewer than 20 cases per week during that month. However, during the first week of December 2013, malaria cases started to rise steadily through to the third week. In the fourth week of December 2013, 
the malaria cases reported at the clinic then exceeded the epidemic threshold. In the first week of January 2014, cases declined to below epidemic threshold but by the second week, the epidemic threshold had been exceeded again to reach a peak of 263 cases in week 3 of January 2014. In week 4 of January 2014, cases continued above the threshold, with 260 cases recorded. The authors in this study sought to determine risk factors for contracting malaria and assess the epidemic preparedness and response in Ward 29 of Shamva District.

\section{Methods}

An unmatched 1:1 case-control study was carried out. A case was defined as a patient who presented at Wadzanayi Clinic with a sudden onset of the following signs and symptoms: intermittent fever, shivering, malaise, joint pains, headache and a positive malaria RDT, between 23 December 2013 and 26 January 2014. A control was defined as a person who stayed in the same neighborhood as the cases but did not develop the symptoms of malaria during the same period. People residing in Ward 29 of Shamva District, listed in treatment records and laboratory registers, and health workers were the study population.

Assuming that $75.4 \%$ of malaria cases engage in outdoor activities with an odds ratio (OR) of 2.97 of contracting the disease, with a power of $80 \%$ and a $95 \%$ confidence interval (CI), the minimum required sample size was 61 cases and 61 controls. Cases were systematically sampled from the clinic's line list. Using the formula $k=N / n$, where $k$ is the sampling interval, $N$ is the number of cases in the line list and $n$ is the sample size, a sampling interval of 15 was calculated. A case was randomly selected from the first 15 malaria patients seen at Wadzanayi Clinic when the epidemic threshold was reached. Thereafter, systematic sampling was used to select every 15th patient from the line list until the required 61 cases were reached. Neighborhood controls were selected by spinning a bottle at the respective case households.

An interviewer-administered questionnaire was used to collect data from cases and controls. Information collected using the questionnaire included demographic variables, risk factors, knowledge variables and treatment given. Health workers on site were selected and interviewed to assess preparedness for and response to the outbreak. An epidemic preparedness and response checklist was adapted for the study. A walk-through assessment of the environment for malaria risk factors was carried out. ORs were computed at a 95\% CI.

Data were analysed using Epi Info 7 (Centers for Disease Control, USA). Stratified analysis and forward stepwise logistic regression analysis were used to control for confounding effect modification.

Ethical approval was granted by the Health Studies Office, University of Zimbabwe and Medical Research Council of Zimbabwe (ref. no. MRCZ/B/879). Written informed consent was obtained from all study participants.

\section{Results}

During the period of the study, 2083 cases of malaria were reported. Three deaths occurred, resulting in a case fatality rate of $0.31 \%$.

Sociodemographic characteristics of cases and controls Cases and controls had comparable sociodemographic features apart from gender and marital status.

\section{Place analysis of the malaria outbreak}

Malaria cases came from Annadale Resettlement Farm (26\%), Richlands Commercial Farm (30\%), the filling station (2\%) and Tipperary Resettlement Farm (11\%).

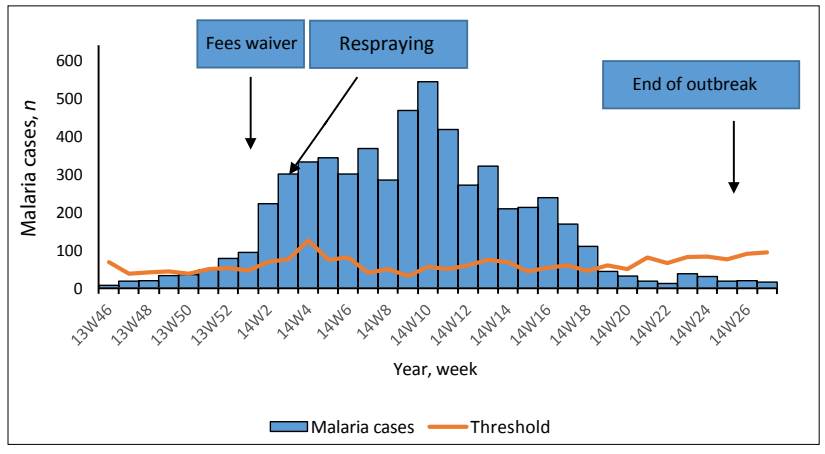

Fig. 1. Epicurve for malaria cases at Ward 29, Shamva, 2014

\section{Time analysis of the malaria outbreak}

Confirmed cases of malaria at Wadzanayi Clinic were below epidemic threshold in November 2013 with less than twenty cases per week during that month (Fig, 1). During the first week of December 2013, malaria cases started to rise steadily through to the third week. In the fourth week of December 2013, malaria cases reported at Wadzanayi Clinic then exceeded the epidemic threshold. In the first week of January 2014, cases declined to below epidemic threshold but the following week the epidemic threshold had been exceeded again to reach a peak of 263 cases in week 3 of January 2014. In week 4 of January 2014, cases continued above the threshold, with 260 cases recorded. The peak was reached in week 1 of March 2014. Cases thereafter declined steadily, albeit above the epidemic threshold until the first week of May 2014. The outbreak was finally declared over in the fourth week of June 2014.

\section{Determinants of contracting malaria}

The risk factors for contracting malaria were performing early morning chores (OR 2.75; 95\% CI 1.20 - 6.32), having a body of water near the home (OR 3.41; 95\% CI 1.62 - 7.20) and having long grass near the home (OR 2.61; 95\% CI 1.10 - 6.37). Protective factors were staying indoors at night (OR 0.13; 95\% CI $0.06-0.28)$ and staying in a home that was sprayed (OR 0.36; 95\% CI $0.21-0.92$ ).

\section{Knowledge about malaria}

Knowledge about malaria transmission or prevention was not significantly associated with contracting malaria.

\section{Independent determinants of malaria in Ward 29, Shamva District}

Independent determinants for contracting malaria were performing early morning chores (AOR (adjusted OR) 3.44; 95\% CI 1.20 - 10.72) and having a body of water near the home (AOR 3.86; 95\% CI 1.61 10.40 ), while staying in a home that was sprayed (AOR 0.37; $95 \%$ CI 0.14 - 0.91) and sitting indoors at night (AOR 0.13; CI $0.05-0.33$ ) were independent determinants for not contracting the disease.

\section{Malaria case management}

All 61 malaria cases were diagnosed with an RDT. All three of the complicated cases were treated with quinine. Four out of 58 simple cases were treated with quinine because of recurrence. The remaining 54 simple cases were treated with co-artemether.

\section{Environmental assessment}

There were numerous bodies of water and Anopheles mosquito breeding sites in Ward 29. Annadale and Tipperary are located in swampy marshlands. The grass surrounding these areas is long. 
Maize fields were sometimes located within a metre of dwellings. There were several stagnant bodies of water nearby. Richlands is located within $1 \mathrm{~km}$ of a large man-made dam. About $47 \%$ of participants lived in modern brick houses while the rest lived in huts and makeshift houses. About $69 \%$ of houses had open eaves.

\section{Epidemic preparedness and response assessment}

The district intervened by announcing a waiver of consultation fees for malaria cases at Wadzanayi Clinic in the second week of January 2014. Respraying was conducted at Annadale Farm starting on 20 January 2014, with 78\% coverage. Epidemic thresholds had been exceeded by 23 December 2013.

\section{Outbreak detection}

Shamva District did not have documented evidence of steps taken in response to the outbreak. Communication between the district health executive and Wadzanayi Clinic was verbal.

\section{Malaria investigation}

A line list of malaria cases was maintained at Wadzanayi Clinic. RDTs were administered to patients suspected of having malaria, and results were provided instantly. The dates when the district was notified were uncertain as these were not documented. There was no epidemiological investigation by the district into drivers of the outbreak. There was no documentation of rapid response team or epidemic preparedness and response committee meetings.

\section{Resource availability \\ Wadzanayi Clinic}

Wadzanayi Clinic had a staff complement of 11, with no vacancies. One primary care nurse was trained in integrated disease surveillance and response and malaria case management. She was on study leave during the outbreak. The village health worker was active, testing for malaria cases and administering treatment. The environmental health technician (EHT) did not have a vehicle and could not travel around the ward carrying out environmental investigations. Malaria threshold graphs were present at the clinic and up to date. Integrated disease surveillance and response guidelines were absent. Surveillance forms for case tallying were available in adequate quantities. IRS coverage for the whole district was $95 \%$ for rooms sprayed. Malaria medicines did not run out during the outbreak. The clinic ordered medicines from Shamva District Hospital. The clinic did not have an inventory control mechanism and ordered medicines as need arose.

\section{Shamva District Hospital}

Shamva District Hospital had two doctors. Two more doctors were seconded from outside the district. Overall, 148 out of 248 village health worker posts were filled. There were four EHT-post vacancies out of 20 in the district. The health information office was manned by a health information officer and an assistant. The hospital did not have up-to-date malaria threshold graphs. T-series forms used for surveillance were present in adequate quantities. The EHTs for Ward 29 covered three wards instead of one. The hospital pharmacy did not have calculated minimum stock levels for all malaria medicines.

\section{Discussion}

Malaria control interventions need to be tailored to the local environment and prevailing risk factors in order to achieve the highest impact using the least resources. According to the World Health Organization (WHO), IRS is considered one of the most promising technologies for reducing the global burden of malaria. ${ }^{[4]}$ In Ward 29 of Shamva District, residing in a house that had had IRS carried out was significantly protective against developing malaria. IRS was carried out in December 2013, when the rainy season had already started. The coverage during this initial exercise was $95 \%$. This is above the WHO standard of at least $80 \%$ coverage of rooms sprayed. ${ }^{[4]}$ Spraying was repeated during the second week of January in response to the malaria outbreak. This second phase of IRS in response to the outbreak may have had little impact as it was done within a month of the previous IRS. This is because the residual activity of the pyrethroids used earlier is longer than 1 month. This response may not have been guided by evidence.

A household randomised trial in Pakistan found mosquito repellents to be protective against Plasmodium falciparum malaria among people from 5 to 20 years old. The mosquito repellent used, Mosbar, was accepted by the community and had very few sideeffects. ${ }^{\left[{ }^{[5]}\right.}$ In our study, staying indoors was found to be protective against contracting malaria. Conversely, outdoor activity increased the risk of contracting malaria. Sharma et al. ${ }^{[6]}$ reported that sleeping indoors is protective, with a statistically significant OR of 0.26 . Our study did not ascertain the reasons for sitting outside at night in Ward 29 of Shamva. The relationship between contracting malaria, outdoor activity and the use of repellants is important for malaria transmission. Personal protective practices such as applying repellent to the skin or wearing long clothes may be of benefit to those who sit outside at night. Health education messages therefore need to be created to discourage people from sitting outside, especially at night. A placebo-controlled trial comparing a commercial repellent, $\mathrm{N}, \mathrm{N}$-diethyl-meta-toluamide (DEET), and placebo demonstrated that skin repellents can provide protection against falciparum malaria infection. This protective effect was greatest among 5 - 20-year-olds, people at the greatest risk of contracting malaria. ${ }^{[7]}$

The use of repellents on the skin in developing countries is problematic. This is because individuals often do not have disposable income and governments do not fund repellent procurement. ${ }^{[8]}$ A study by Lukwa et al..$^{[9]}$ in the Honde Valley, Zimbabwe, found that $23.5 \%$ of study participants had applied plant extracts to their skin as mosquito repellents. In our study, only $1.6 \%$ of respondents mentioned skin repellents as a malaria prevention method. However, residents of Ward 29 may well benefit from the application of such skin repellents, as $72 \%$ of them engaged in early morning chores and $50 \%$ sat outside at night. This intervention may require intensive health education before being rolled out.

Shamva District is located in natural region 1 . This region has predominantly intensive farming activity resulting in $75-80 \%$ of the area being planted with crops. ${ }^{[10]}$ Ward 29 of Shamva District has both commercial farms and subsistence farms. Annadale and Tipperary are former commercial farms that were converted into small-scale plots under the Land Resettlement Programme in Zimbabwe. The rainy season resulted in an increase in stagnant bodies of water around these settlements. Richlands Farm has a large man-made dam that is about $20 \mathrm{~m}$ adjacent to a compound housing farm workers. The dam provided a site for increased mosquito breeding, which resulted in an increased risk of contracting malaria, as shown by our study. A study on environmental determinants of malaria in Peru suggested that residing in close proximity to bodies of water and irrigation sites poses a significant risk for contracting malaria. ${ }^{[1]}$ The WHO recommends larviciding where breeding sites are few, fixed and findable. ${ }^{[12]}$ The study setting had several bodies of water, some of which were not fixed. Larval source management by 
larviciding, however, remains an option as this study clearly shows the risk posed by bodies of water.

In our study, a history of malaria was found to be associated with contracting malaria, but this relationship was not statistically significant. According to the Wellcome Trust, repeated attacks of malaria may result in partial immunity. ${ }^{[13]} \mathrm{A}$ total of $87.6 \%$ of those with a history of malaria had contracted it in the previous two rainy seasons, but this period is not expected to result in partial immunity. Shamva has unstable malaria transmission. The previous two seasons have been characterised by back-to-back malaria outbreaks. This may well reflect the unstable transmission of malaria in the area

The shortage of EHTs negatively affected malaria-control activities in the study area. The EHT stationed at Wadzanayi Clinic covered three wards instead of just one. This may have resulted in the poor outbreak response noted during our study. The district had poor documentation of key steps in response to the outbreak. This created difficulties in assessing preparedness and response to the outbreak.

User fees are a barrier to achieving universal healthcare. ${ }^{[14]}$ In this study, the waiver of user fees may have resulted in late treatment of malaria cases. Health authorities need to explore ways of protecting citizens against this potential barrier. The district reported that user fees for malaria cases had been scrapped in response to the outbreak. However, malaria was only diagnosed after a patient had been charged for the initial consultation. This creates reservations about the effectiveness of this intervention, as patients were not being reimbursed the consultation fee after being diagnosed with malaria.

Most of the nurses at Wadzanayi Clinic were not trained in integrated disease surveillance and response, or malaria case management. This may have resulted in the poor response to the outbreak noted during our study. The absence of inventory control systems at Wadzanayi Clinic may lead to future stock-outs. The lack of an inventory control system at the district hospital may also compound the problem. In Kenya, poor inventory control led to stock-outs of antimalaria medicines. ${ }^{\left[{ }^{[15]}\right.}$ While the malaria outbreak is now long gone, health system weaknesses identified by the authors have the potential to recur or persist and result in similar outbreaks in the future. As of December 2016, Zimbabwe continues to face critical health worker shortages owing to a recruitment freeze on health posts. ${ }^{[16]}$ The role of larviciding for malaria prevention where there are significant and numerous but easily identified breeding sites needs further exploration. The applicability, effectiveness and cost-effectiveness of personal protective measures, especially where outdoor biting and outdoor activity are common, needs further exploration.

\section{Public health actions taken}

The results of the study were shared with Wadzanayi Clinic staff and the district health executive for public health action. Stock-control weaknesses at the district hospital and clinic were immediately rectified via the use of stock cards. Malaria case management training was rolled out to untrained nurses and EHTs with support from the Global Fund in 2015. An oral presentation of the study findings was made at the Zimbabwe Annual Malaria Conference in August 2015.

\section{Study limitations}

Owing to the study design, recall bias may be a limitation as study participants were responding to questions about the past. Microscopic confirmation of malaria was not done following a positive RDT. This may have led to the recruitment of participants infected outside the outbreak duration, especially in the initial stages of the outbreak.

\section{Conclusion}

Risk factors for contracting malaria in Ward 29 of Shamva District were performing early morning chores and having bodies of water near homes. Protective factors were staying indoors at night and staying in a home that was sprayed. The malaria response by the district was inadequate and poorly documented. Medicines inventory control needs urgent review in view of the protracted duration of the outbreak. Personal protective measures, larval source management and health education remain important malaria control measures. This study emphasises the need for malaria interventions to be tailored to locally prevailing determinants in order to avert outbreaks. and Quality in Health - A People's Right. Harare: Ministry of Health and Child Welfare Zimbabwe, 2009. http://www.nationalplanningcycles.org/sites/default/files/country_docs/Zimbabwe/national_ health_strategy_2009-2013-final.pdf (accessed 11 December 2016).

2. Ministry of Health and Child Welfare. National Malaria Control Programme Strategy, 2008 - 2013. Harare: Ministry of Health and Child Welfare Zimbabwe, 2009. http://www.rollbackmalaria.org/files/ files/countries/zimbabwe2008-2013.pdf (accessed 11 December 2016).

3. Sinclair D, Zani B, Donegan S, Olliaro P, Garner P. Artemisinin-based combination therapy for treating uncomplicated malaria. Cochrane Database Syst Rev 2009;3. http://dx.doi.org/10.1002/14651858.CD007483. pub2

4. World Health Organization. Indoor residual spraying: Use of indoor residual spraying for scaling up global malaria control and elimination. Geneva: WHO, 2006. http://apps.who.int/iris/ bitstream/10665/69386/1/WHO_HTM_MAL_20061112 eng pdf (accessed 11 December 2016).

Towland M. DEET mosquello Rowland M. DEET mosquito repellent provides personal protection against malaria: A household randomized trial in an Afghan refugee camp in Pakistan. Trop Med Int Health 2004;9(3):335-342.

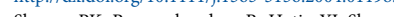

6. Sharma PK, Ramanchandran R, Hutin YJ, Sharma R, Gupte MD. A malaria outbreak in Naxalbari, Darjeeling district, West Bengal, India, 2005: Weaknesses in disease control, important risk factors. Malar J 2009;8(288). http://dx.doi.org/10.1186/1475-2875-8-288

7. Beever R. Mosquito repellent effectiveness: A placebo controlled trial comparing 95\% DEET, Avon Skin So Soft, and a 'special mixture' containing eucalyptus oil. B C Med J 2009;48(5):226-231. http:// www.bcmj.org/article/mosquito-repellent-effectiveness-placebo-controlled-trial-comparing-95-deetavon-skin-so-sof (accessed 11 December 2016).

8. Frances SP, Wirtz RA. Repellents: Past, present and future. J Am Mosq Control Assoc 2005;21(4):1-3. https://dx.doi.org/10.2987/8756-971X(2005)21[1:RPPAF]2.0.CO;

9. Lukwa N, Nyazema NZ, Curtis CF, Mwaiko GL, Chandiwana SK. People’s perceptions about malaria transmission and control using mosquito repellent plants in a locality in Zimbabwe. Cent Afr I Med 1999;45(3):64-68. http//:dx.doi.org/10.4314/cajm.v45i3.8456

10. Mugandani R, Wuta M, Makarau A, Chipindu B. Reclassification of agro-ecological regions of Zimbabwe in conformity with climate variability and change. Afr Crop Sci J 2012;20(2):361-369. Zimbabwe in conformity with climate variability and change. Afr Crop Sci I 2012;20(2):361-369.
http://www.ajol.info/index.php/acsj/article/download/81761/71908 (accessed 11 December 2016).

11. Guthmann JP, Hall AJ, Jaffar S, Palacios A, Lines J, Llanos-Cuentas A. Environmental risk factors for clinical malaria: A case-control study in the Grau region of Peru. Trans R Soc Trop Med Hyg 2001;95(6):577-583. http://dx.doi.org/10.1016/S0035-9203(01)90084-7

12. World Health Organization. Larval Source Management: A Supplementary Measure for Malaria Vector Control. An Operational Manual. Geneva: WHO, 2006. http://www.who.int/malaria/publications/ atoz/larval_source_management_2-pager_eng.pdf?ua= (accessed 11 December 2016).

13. Wellcome Trust. Immunity to malaria. $2004 \mathrm{http}: / /$ malaria.wellcome.ac.uk/doc_WTD023885.html (accessed 7 August 2014).

4. Yates R. Universal health care and the removal of user fees. Lancet 2009;373(9680):2078-2081. http:// dx.doi.org/10.1016/S0140-6736(09)60258-0

15. Kangwana BB, Njogu J, Wasunna B, et al. Malaria drug shortages in Kenya: A major failure to provide access to effective treatment. Am I Trop Med Hyg 2009:80(5):737-738. http://www.aitmh org/ content $/ 80 / 5 / 737$ full.pdf + html (accessed 11 December 2016).

16. Global Fund Office of the Inspector General. Audit Report: Global Fund Grants to the Republic of Zimbabwe 2016. https://www.google.com.eg/url? sa $=t \& r c t=j \& q=\&$ esrc $=s \&$ source $=$ web\& $\& d=23 \& c a d=r j$

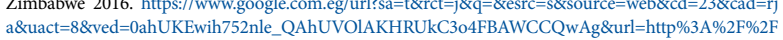
www.theglobalfund.org\%2Fdocuments\%2Foig\%2Freports\%2FOIG_GF-OIG-16019_Report_en\%2F\&u sg=AFQjCNFmxcsMQG3yQmcyylVl__3R5mavzw\&bvm=bv.141320020,d.d2s (accessed 11 December $\mathrm{sg}=\mathrm{AFQ}$
$2016)$.

Accepted 10 January 2017 